\title{
А.Э. Эргешов
}

Центральный научно-исследовательский институт туберкулеза, Москва, Российская Федерация

\section{Туберкулез в Российской Федерации: ситуация, проблемы и перспективы}

\begin{abstract}
Туберкулез является значимой проблемой общественного здравоохранения как в России, так и в мире. Около 1/3 населения мира инфицировано микобактериями туберкулеза. Ежегодно в мире регистрируется более 10 млн новых случаев заболевания туберкулезом, и около 1,7 млн человек умирает от него. В Российской Федерации в результате мер, предпринятых правительством и органами здравоохранения, эпидемическая ситуация по туберкулезу после резкого ухудшения в 90-е годы прошлого века заметно улучшилась. В то же время рост числа случаев туберкулеза, вызванного лекарственно-устойчивыми микобактериями туберкулеза, и низкая эффективность его лечения, сочетание ВИЧ-инфекции и туберкулеза снижают результативность противотуберкулезных мероприятий. Научные исследования, проводимые ЦНИИТ, который является Сотрудничающим центром ВОЗ по туберкулезу в РФ, направлены на решение таких актуальных задач, как изучение механизмов латентной инфекиии, разработка тест-систем для ускоренной диагностики лекарственной устойчивости, клиническая апробация и внедрение коротких эффективных режимов химиотерапии, разработка новых лекарственных препаратов. Успехи, достигнутые к ХХІ веку в изучении туберкулеза, создают предпосылки для того, чтобы ликвидировать его эпидемию как в мире, так и в России, хотя говорить о близкой победе над туберкулезом пока рано.
\end{abstract}

Ключевые слова: туберкулез, микобактерия туберкулеза, лекарственная устойчивость, химиотерапия.

(Для цитирования: Эргешов А.Э. Туберкулез в Российской Федерации: ситуация, проблемы и перспективы. Вестник РАMН. 2018;73(5):330-337. doi: 10.15690/vramn1023)

\section{Современная эпидемиология туберкулеза}

Туберкулез (ТБ) является значимой проблемой общественного здравоохранения как в России, так и в мире. Около $1 / 3$ населения планеты инфицировано микобактериями туберкулеза (МБТ). Ежегодно в мире регистрируется около 10 млн новых случаев заболевания ТБ, а около 1,7 млн человек умирают от ТБ. Настораживает и тот факт, что доля больных ТБ в сочетании с ВИЧ-инфекцией или ТБ с множественной лекарственной устойчивостью (МЛУ) возбудителя, т.е. лекарственной резистентностью как минимум к двум основным противотуберкулезным препаратам - изониазиду и рифампицину, увеличивается. Так, по данным Всемирной организации здравоохранения (ВО3), количество больных ТБ, ассоциированным с вирусом иммунодефицита человека (ВИЧ), составляет 1,03 млн человек, а ТБ с МЛУ - 490000 человек, и почти каждый второй из них в последующем умирает [1].
Эпидемиологическая ситуация по ТБ в Российской Федерации (РФ) остается напряженной. Пик показателей заболеваемости и смертности от ТБ пришелся на начало XXI века, когда в 2000 г. заболеваемость достигла 90,4 на 100000 населения, а смертность от туберкулеза в 2005 г. 22,6 на 100000 населения (рис. 1).

Благодаря эффективным мерам, предпринятым правительством и органами здравоохранения РФ, эпидемическая ситуация по ТБ в 90-е годы прошлого века заметно улучшилась: по данным Росстата, заболеваемость ТБ снизилась на 46,6\%, или в 1,9 раза (с 90,4 на 100000 населения в 2000 г. до 48,3 в 2017), смертность от ТБ - на 71,7\%, или в 3,5 раза (с 22,6 до 6,4 соответственно). Средние темпы снижения смертности в последние годы составляют около $10 \%$ в год.

В ближайшем будущем на эпидемиологический процесс будут по-прежнему отрицательно влиять рост доли больных МБТ с МЛУ к противотуберкулезным препаратам и развивающаяся эпидемия ВИЧ-инфекции с ростом

\author{
A.E. Ergeshov \\ Central TB Research Institute (CTRI), Moscow, Russian Federation
}

\section{Tuberculosis in the Russian Federation: Situation, Challenges and Perspectives}

Tuberculosis (TB) is a significant problem of public health both in Russia and abroad. About one third of the world's population is infected with Mycobacterium tuberculosis. Every year more than 10 million new TB cases are registered in the world, and about 1.7 million people die from $T B$. In the Russian Federation, due to the measures taken by the Government and health authorities the epidemic TB situation has been noticeably improved since the sharp deterioration in the 90s of the last century. At the same time, the spread of drug-resistant TB and its low treatment effectiveness, the spread of combined HIV and TB infection reduces the effectiveness of anti-tuberculosis interventions. The research conducted by CTRI, the WHO Collaborating Center for TB in the Russian Federation, is aimed at solving such urgent problems as studying latent infection mechanisms, developing new test systems for accelerated diagnostics of drug resistance, clinical approbation and introduction of short effective regimens of chemotherapy, developing new antituberculosis agents. The achieved successes in the study of tuberculosis in the 21st century creates preconditions for eliminating its epidemic both in Russia and the world, though suggesting imminent breakthrough for tuberculosis is a hasty conclusion.

Key words: tuberculosis, Mycobacterium tuberculosis, drug resistance, chemotherapy.

(For citation: Ergeshov AE. Tuberculosis in the Russian Federation: Situation, Challenges and Perspectives. Annals of the Russian Academy of Medical Sciences. 2018;73(5):330-337. doi: 10.15690/vramn1023) 

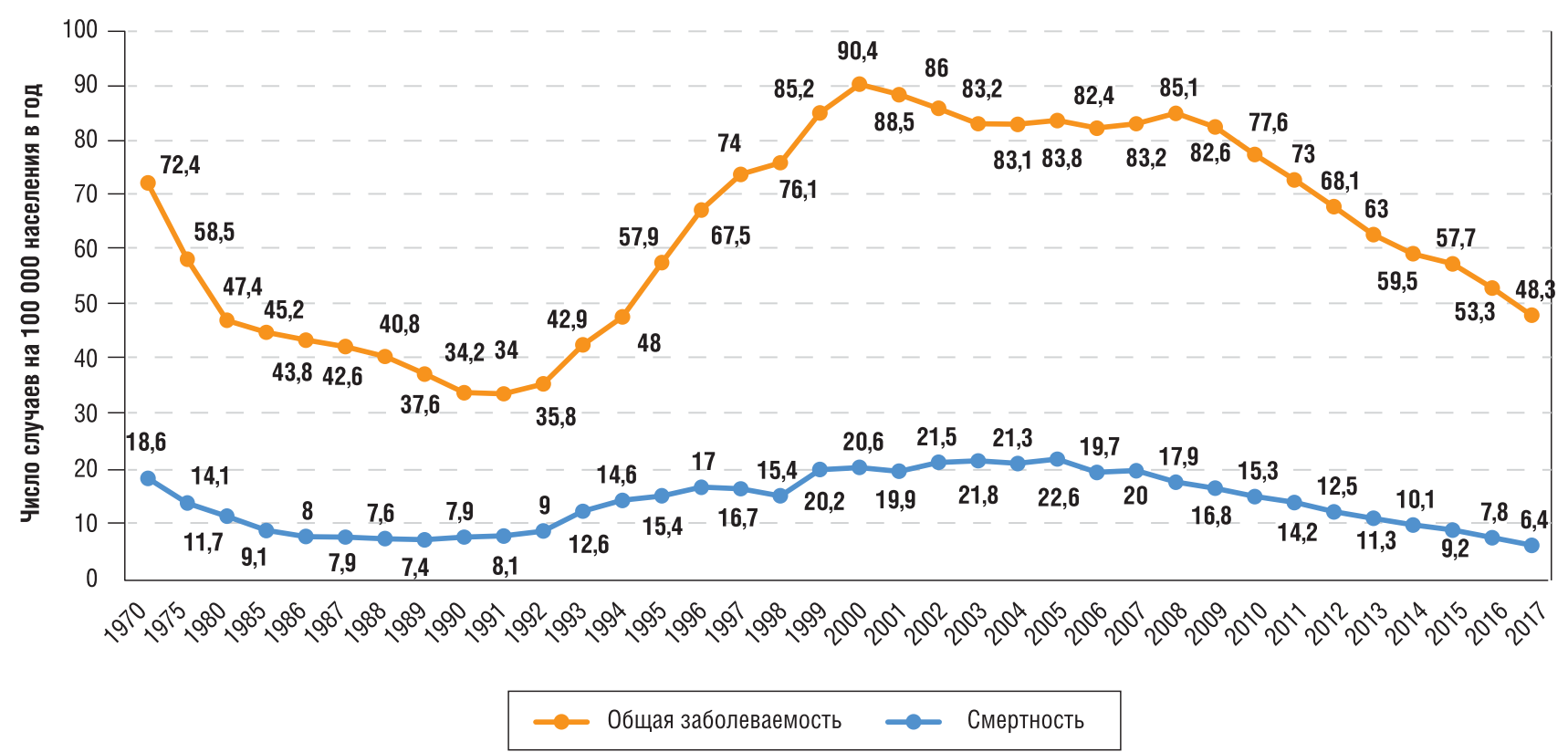

Рис. 1. Заболеваемость и смертность от туберкулеза в Российской Федерации в 1970-2017 гг.

числа и доли пациентов с поздними ее стадиями в сочетании с ТБ, обусловленные в том числе миграцией населения. Так, доля пациентов с МЛУ ТБ среди впервые выявленных больных ТБ органов дыхания, выделяющих МБТ, составляет $27,4 \%$, а среди ранее пролеченных - более половины случаев (54\%). Доля пациентов с ТБ, сочетанным с ВИЧ-инфекцией, с 2009 по 2017 г. увеличилась более чем в 3 раза как среди впервые выявленных (с 6,5 до 20,9\%), так и среди ранее пролеченных (с 5,5 до 18,5\%) (рис. 2).

Доля мигрантов среди впервые выявленных больных ТБ значительна и варьирует в широких пределах: в Мо-

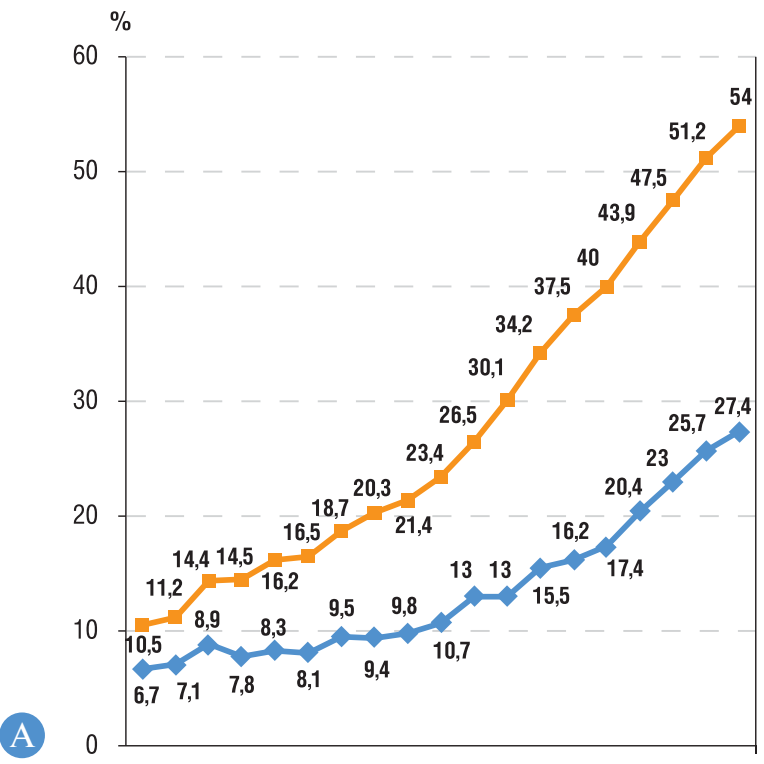

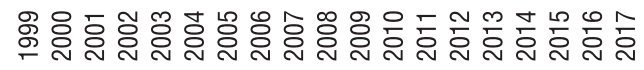

\footnotetext{
ح Доля МЛУ среди впервые выявленных случаев туберкулеза

- Доля Млу среди контингентов больных туберкулезом
}

сковской обл. $-7,1 \%$, в Калужской обл. $-26 \%$, в Москве $-31,7 \%$.

Тем не менее успехи, достигнутые в борьбе с ТБ в XXI веке, дали Всемирной организации здравоохранения основание принять Глобальную стратегию в области профилактики, лечения и борьбы с туберкулезом на период после 2015 г. Основная цель стратегии ВОЗ - ликвидировать глобальную эпидемию ТБ: мир без ТБ, без смертей, заболеваний и страданий от ТБ. Предусматривается снижение числа умерших от ТБ на $35 \%$ с 2015 к 2020 г., к 2025 - на $75 \%$, к 2030 - на $90 \%$, к 2035 - на $95 \%$ и

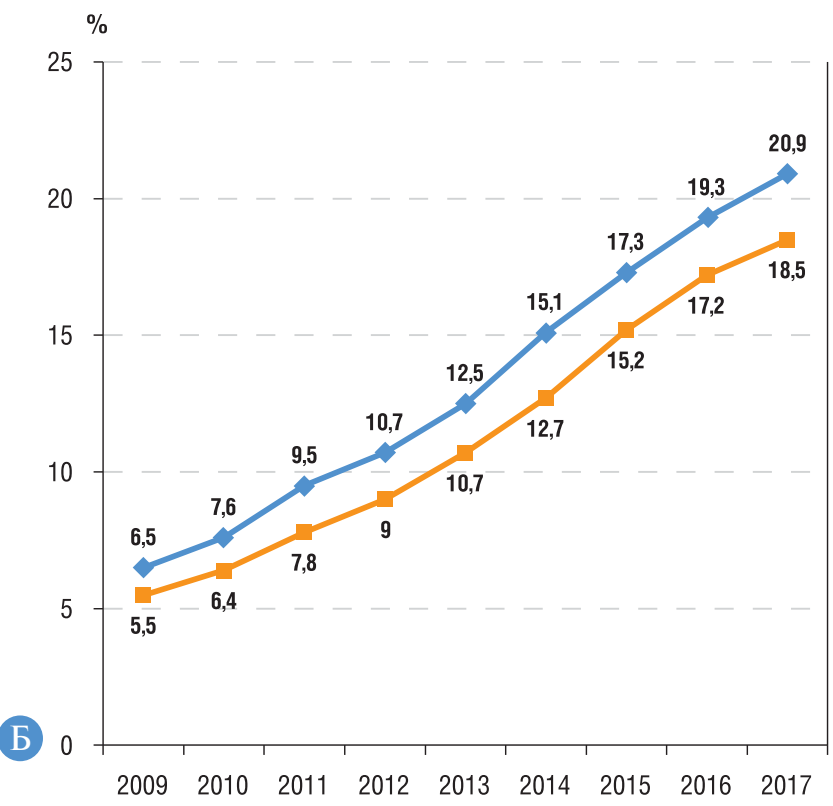

\footnotetext{
- Туберкулез, сочетанный с ВИЧ-инфекцией, среди впервые выявленных больных туберкулезом

- Туберкулез, сочетанный с ВИЧ-инфекцией, среди контингентов больных туберкулезом
}

Рис. 2. Эпидемиологический процесс по туберкулезу в Российской Федерации

Примечание. А - туберкулез с множественной лекарственной устойчивостью возбудителя (МЛУ ТБ) в России в 1999-2017 гг. (форма федерального статистического наблюдения № 33); Б - туберкулез, сочетанный с ВИЧ-инфекцией, 2009-2017 гг. (ФСН № 33). 
снижение показателя заболеваемости с 2015 к 2020 г. на $20 \%(<85 / 100000)$, к 2030 - на 90\% (20/100 000), к 2035 на $95 \%(<10 / 100000)$.

Впервые в истории ВОЗ в ноябре 2017 г. в Москве прошла первая Глобальная министерская конференция ВО3 «Ликвидировать туберкулез. Многосекторальный подход». В Московской декларации сформулированы ключевые стратегические направления и первоочередные мероприятия по ликвидации ТБ в мире. Основные направления и первоначальные мероприятия должны быть ориентированы на разработку новых диагностических алгоритмов, мер биологической безопасности. Особое внимание должно быть уделено подготовке и переподготовке кадров, осуществляющих профилактику, диагностику и лечение ТБ; разработке и быстрому внедрению новых лекарственных средств, укороченных режимов лечения; межсекторальному подходу к решению проблемы доступности медицинской помощи.

Основные научные направления ФГБНУ «Центральный научно-исследовательский институт туберкулеза» (далее ЦНИИТ) предусматривают изучение биологических свойств МБТ, разработку быстрых методов диагностики ТБ, разработку и испытание новых поколений химиопрепаратов и вакцин, совершенствование режимов химиотерапии и решение ряда других проблем.

\section{Микробиология и молекулярная генетика микобактериальных инфекций}

Огромное значение в развитии научных исследований имеет работа в области микробиологии и молекулярной генетики микобактериальных инфекций. Она направлена как на осуществление фундаментальных, так и прикладных образовательных программ. Особую актуальность в настоящее время приобретает сокращение сроков диагностики ТБ, т.к. микобактерии являются трудно культивируемыми и медленно растущими патогенами. Сроки получения результата микробиологической диагностики ранее могли достигать 12 нед. В ЦНИИТ разработаны и внедрены передовые технологии, направленные на ускоренное получение результата исследования в сочетании с высокой надежностью [2-5].

Автоматизация диагностики методом полимеразной цепной реакции (ПЦР), основанная на внедрении в диагностические исследования автоматизированной станции (Freedom EVO 150, Теcan, Швейцария) с разработкой как технологии, так и оригинальной управляющей программы, позволила повысить чувствительность молекулярно-генетических тестов, снизить вероятность контаминации при выделении ДНК, сократить трудозатраты и существенно увеличить поток проводимых исследований до 90 образцов диагностического материала в день [6].

С целью обеспечения биобезопасности был создан и всесторонне протестирован инактивирующий реагент, обладающий стерилизующей активностью в отношении микобактерий и одновременно повышающий выход ДНК [7].

Для экспресс-детекции устойчивости к рифампицину, изониазиду и фторхинолонам совместно с ООО «Синтол» были разработаны ПЦР тест-системы, позволяющие определить лекарственную устойчивость МБТ в течение 3 ч. Все тест-системы прошли клинические испытания и зарегистрированы в соответствии с российским законодательством $[8,9]$.
Разработанные совместно с Институтом молекулярной биологии РАН биологические микрочипы выявляют лекарственную устойчивость по большему числу мутаций в целевых генах в течение 24 ч, а также сполиго-биочипы, которые позволяют проводить дифференциацию видов возбудителя ТБ внутри туберкулезного комплекса и определять основные генотипические линии МБТ, что важно с эпидемиологической и клинической точки зрения [10-13].

Актуальными являются фундаментальные исследования нетуберкулезных микобактерий [14-17]. В ЦНИИТ исследования нетуберкулезных микобактерий направлены на создание тест-систем для ускоренной диагностики микобактериоза и изучение генома возбудителей. Оригинальной разработкой является создание ПЦР тест-системы, позволяющей непосредственно в диагностическом материале определять одновременно наличие ДНК МБТ и 14 основных клинически значимых видов нетуберкулезных микобактерий для их дифференциации [18].

В рамках изучения особенностей генома нетуберкулезных микобактерий проведено полногеномное секвенирование ДНК трех штаммов нетуберкулезных микобактерий видов Mycobacterium gordonae, Mycobacterium malmoense и Mycobacterium heckeshornense, сборки геномов которых были депонированы в базу данных GenBank NCBI (Национальный центр биотехнологической информации, США) [19, 20].

Для изучения видового разнообразия нетуберкулезных микобактерий применяется массспектрометрический анализ, характеризующий индивидуальные профили рибосомальных белков. Ученые ЦНИИТ охарактеризовали спектры более чем 20 видов нетуберкулезных микобактерий, включенных в базу данных MALDI Biotyper systems (Bruker Corporation, Германия), которая используется лабораторными специалистами мирового сообщества для идентификации выявляемых микроорганизмов [21, 22].

Перспективное направление научных исследований связано с таргетным секвенированием генов для поиска основ лекарственной резистентности МБТ, особенно к резервным противотуберкулезным препаратам, а также различных видов нетуберкулезных микобактерий [23-27].

Развитие молекулярно-эпидемиологических исследований в ЦНИИТ позволило описать основные генетические линии МБТ, циркулирующих на отдельных территориях РФ. Еще в 2003 г. было показано преобладание МБТ линии W-Beijing. В РФ были выделены МБТ линий Haarlem, LAM и T, каждая из которых представлена несколькими сублиниями [28].

Изучение генетического полиморфизма штаммов Mycobacterium tuberculosis, выделенных от ВИЧпозитивных и ВИЧ-негативных больных ТБ, показало большую кластеризацию (меньшее разнообразие) штаммов МБТ, выделенных от ВИЧ-позитивных больных. Полученные результаты могут служить основой к совершенствованию противоэпидемических и лечебно-диагностических мероприятий в отношении микобактериальных инфекций у ВИЧ-инфицированных лиц [29].

Молекулярно-эпидемиологические исследования распространенности нетуберкулезных микобактерий показали видовое разнообразие нетуберкулезных микобактерий, циркулирующих на различных территориях РФ. Описано преобладание и отсутствие отдельных видов нетуберкулезных микобактерий в ряде регионов [30]. 


\section{Иммунологические методы диагностики туберкулеза}

Далеко не во всех случаях в исследуемом материале удается обнаружить возбудитель ТБ, особенно у детей при ограниченных формах процесса, поэтому важная роль в диагностике ТБ принадлежит иммунологическим методам, которые также позволяют получить важную информацию об инфицированности населения МБТ.

Для определения инфицирования наиболее широко распространены кожные пробы, которые применяются уже около сотни лет. Наряду с пробой Манту с 2 TЕ туберкулина Линниковой, традиционно применявшейся в нашей стране, в последние годы получила широкое распространение проба с антигеном туберкулезным рекомбинантным (Диаскинтест). Эта проба способна дифференцировать состояние инфицированности МБТ от поствакцинной аллергии [31]. Кожные пробы являются важными для определения инфицированности населения и выявления лиц, требующих дообследования на предмет наличия у них активного ТБ.

Вместе с тем необходимо учитывать, что ни один из применяемых для данных целей способов не гарантирует стопроцентной уверенности в истинности получаемого результата. Наблюдения показывают, что в очагах заражения или в случаях высокой региональной заболеваемости ТБ кожные пробы у ряда лиц остаются отрицательными, несмотря на высокую вероятность инфицирования.

В диагностике ТБ и его дифференциальной диагностике с другими заболеваниями особое значение приобрели способы, основанные на определении специфического иммунного ответа к антигенам МБТ. Это касается и серологических методов, которые основаны на выявлении антител к антигенам МБТ или самих антигенов микобактерий в биологических жидкостях. Преимуществом данных методов являются скорость и простота постановки теста, относительно низкая стоимость и выполнение в условиях in vitro. Существенный недостаток большинства серологических тестов - их невысокие чувствительность и специфичность.

На сегодняшний день наиболее широко для диагностики ТБ используются так называемые интерфероновые тесты (IGRAs), основанные на оценке антигениндуцированной продукции интерферона (interferon, IFN) $\gamma$ клетками крови. В качестве антигенов в тестах IGRAs используют специфичные антигены для вирулентной культуры микобактерий (EAST-6, CFP-10). В тесте QuantiFERON-TB Gold In-Tube определяют уровень стимулированной продукции IFN $\gamma$ клетками крови. В тест-системе T-SPOT определяют количество клеток, продуцирующих IFN $\gamma$ в ответ на стимуляцию указанными антигенами. Многочисленные исследования, посвященные диагностике ТБ, выявили, что в регионах с высокой распространенностью ТБ чувствительность тестов IGRAs невысока, что обусловлено присутствием в популяции большого числа больных с длительно текущим ТБ и частым развитием анергии. Так, в Индии положительные результаты QuantiFERON-TB Gold InTube отмечались у 44 из 60 больных с подтвержденным диагнозом ТБ (73\%), в Гамбии - у 52 из 80 (64\%), в Южной Африке - у 103 из 136 (76\%), в Индонезии - у 82 из $93(89 \%)$ [32-34].

Определение специфичности IGRAs показало, что в регионах с высокой распространенностью ТБ около $50 \%$ обследованных людей без признаков заболевания ТБ имели положительные результаты тестов IGRAs. Напро- тив, в регионах с низкой распространенностью ТБ специфичность тестов превышает 90\% [35, 36].

Следовательно, несмотря на то, что в странах с низкой распространенностью ТБ методы IGRAs успешно применяются как скрининговые, с их помощью невозможно отличить латентную инфекцию от активного процесса, что ограничивает их использование в регионах с высокой распространенностью инфекции.

Для разграничения активного ТБ и латентной инфекции предложено определение содержания в крови лимфоцитов, отвечающих на стимуляцию антигенами МБТ продукцией сразу нескольких цитокинов (полифункциональные лимфоциты) или только одного цитокина (монофункциональные лимфоциты). Определение таких лимфоцитов проводят с помощью проточной цитометрии [37-39].

Важным показателем состояния Т-клеточного иммунитета является не только способность лимфоцитов Th1 к продукции цитокинов, но и степень их дифференцировки. Исследования, проведенные в последние годы, в том числе в ЦНИИТ, показали, что активный ТБ сопровождается образованием в легочной ткани и постепенным накоплением в крови высокодифференцированных эффекторных лимфоцитов $\mathrm{CD} 4^{+}$, имеющих фенотип CD27-. По нашим предварительным данным, содержание МБТ-специфичных клеток $\mathrm{CD} 4{ }^{+} \mathrm{CD} 27^{-}$ выше 31,2\% позволяет дифференцировать активный ТБ от инфицирования с чувствительностью $82 \%$ и специфичностью $90 \%$ [40].

Таким образом, в настоящее время иммунологические методы находят широкое применение для выявления заболевания и инфицирования ТБ. Вместе с тем детекция инфицированности и/или заболевания ТБ с помощью одного из иммунологических методов может дать ошибочный ответ в силу генетически детерминированных особенностей отдельных индивидуумов. Более точные сведения могут быть получены лишь при комплексном обследовании.

\section{Новые направления диагностики туберкулеза и изучения механизмов формирования лекарственной устойчивости возбудителя}

Важное значение приобретает научное решение проблемы формирования механизмов лекарственной устойчивости соматических клеток к противотуберкулезным препаратам. К настоящему времени в эпителиальных и макрофагальных клетках легкого обнаружено присутствие четырех транспортных белков (MDR1, MRP1, BCRP и LRP), ответственных за развитие МЛУ [41, 42]. Они функционируют в качестве «насосов», постоянно выводящих во внешнюю среду токсические вещества (лекарственные препараты), тем самым препятствуя их накоплению в тканях легкого и очагах воспаления [43]. В этой связи необходимо изучить влияние разных факторов туберкулезного воспаления на экспрессию белков МЛУ и на фармакокинетику противотуберкулезных препаратов при химиотерапии ТБ. В настоящее время разрабатывается методическая база для оценки экспрессии белков МЛУ в операционном материале больных, длительно получавших противотуберкулезные препараты, с целью своевременной коррекции и повышения эффективности проводимого лечения.

Одним из современных методов выявления МБТ в легочной ткани является лазерная сканирующая 
конфокальная микроскопия, для чего могут быть использованы гистологические срезы толщиной 50-60 мкм. Это значительно расширяет диагностические возможности изучения клинического материала, позволяет выявить одиночные формы возбудителя, оценить его локализацию в разных зонах туберкулезного воспаления [44]. Проведение 3D-реконструкции проанализированных срезов позволяет составить представление о численности и особенностях распределения колоний МБТ в тканях.

Важным преимуществом метода является возможность проведения анализа спектров испускания флуоресценции различных структур, локализованных в исследованных образцах и сходных (по своим размерам и форме) с МБТ [45]. Это позволяет исключить неспецифическую люминесценцию объектов исследования и обеспечить достоверность полученных результатов.

В диагностике ТБ важная роль принадлежит эндоскопическим методам, которые помогают получить информативный диагностический материал при подозрении на ТБ или установить альтернативный диагноз.

\section{Повышение эффективности лечения больных туберкулезом}

Основой современного лечения пациентов с ТБ является противотуберкулезная химиотерапия, которая заключается в длительном применении оптимальной комбинации лекарственных препаратов, уничтожающих МБТ или подавляющих их размножение в организме пациента. В зависимости от лекарственной чувствительности возбудителя пациентам назначают один из 5 стандартных режимов химиотерапии, длительность которых варьирует от полугода до 2 лет, а количество применяемых противотуберкулезных препаратов - не менее трех.

Результаты лечения в значительной степени зависят от своевременного выявления лекарственной устойчивости МБТ. По данным ВОЗ за 2016 г., эффективность лечения больных ТБ в мире составила $83 \%$ при отсутствии лекарственной устойчивости МБТ, в то время как у пациентов с МЛУ МБТ она не превышала $52 \%$, а при наличии широкой лекарственной устойчивости МБТ $26 \%$ [1]. Эффективность лечения в группе больных с МЛУ МБТ, получавших IV режим химиотерапии, значительно выше по клинико-лабораторным показателям в случаях ускоренного определения рифампицин-резистентности молекулярно-генетическими методами: устранение интоксикационного синдрома к 4-му месяцу лечения наступило у $78 \%$ пациентов группы с ранним назначением химиотерапии по сравнению с 54\% больных, получавших отсроченное лечение $(p<0,05)$ [46].

В ЦНИИТ получен первый опыт применения нового противотуберкулезного препарата - бедаквилина - для лечения больных с широкой лекарственной устойчивостью МБТ. Включение бедаквилина в комбинацию противотуберкулезных препаратов по V режиму химиотерапии позволяло добиться более раннего прекращения бактериовыделения и лучшей рентгенологической динамики изменений в легких. Показана возможность совместного применения бедаквилина и моксифлоксацина, которое не приводило к увеличению интервала QT у большинства больных [47].

Важный вклад в комплексное лечение больных ТБ вносят современные эндоскопические методы:

- ригидная бронхоскопия высокого разрешения значительно расширяет возможности бронхолога при выполнении эндобронхиальных оперативных вмешательств;

- перибронхиальные инъекции противотуберкулезных препаратов у пациентов с ТБ трахеи и бронхов позволяют значительно ускорить прекращение бактериовыделения и избежать формирования рубцовых стенозов дыхательных путей;

- клапанная бронхоблокация за счет управляемого ателектаза легочной ткани с помощью однонаправленного эндобронхиального клапана позволяет эффективно редуцировать как туберкулезные, так и поствоспалительные каверны в легочной ткани.

Приоритетной задачей хирургического отдела ЦНИИТ является выполнение обширных хирургических вмешательств с максимальным сохранением функциональных резервов и внешнего вида пациентов при объеме операции, адекватном распространенности и характеру туберкулезного процесса.

В соответствии с поставленной задачей в последние годы были разработаны инновационные хирургические технологии:

- бескультевая обработка главного бронха при пневмонэктомии с применением высокоэнергетического лазера и оригинальной методики плевризации культи, что обеспечивает раннюю васкуляризацию в условиях асептического некроза (во время плевризации листки плевры фиксируются к ручному шву культи, исключая околокультевое недренируемое пространство, которое может служить источником воспаления и несостоятельности);

- технология этапного хирургического лечения двустороннего деструктивного туберкулеза легких с применением экстраплеврального пневмолиза с пломбировкой силиконовым имплантатом на стороне наименьшего и плевропневмонэктомии - на стороне наибольшего поражения позволяет улучшить состояние больного за счет прекращения перерастяжения ткани легкого и улучшения вентиляции;

- деструкция высокоэнергетическим лазером туберкулезных очагов в оставляемом легком при резекционных операциях показана при снижении дыхательных резервов с потенциальным развитием у больных дыхательной недостаточности в случае выполнения резекции легкого;

- пластика переднего средостения при пневмонэктомии позволяет надежно предотвратить формирование легочной грыжи после операции, избежать серьезных осложнений и улучшить качество жизни больных.

Дифференцированный подход к определению сроков лечения после операции, с одной стороны, позволит уменьшить риск развития рецидива заболевания, с другой - избежать необоснованно длительной химиотерапии. В соответствии с Федеральными клиническими рекомендациями по диагностике и лечению туберкулеза длительность химиотерапии в послеоперационном периоде должна составлять не менее 6 мес при сохраненной лекарственной чувствительности МБТ и не менее 12 мес при множественной/широкой лекарственной устойчивости возбудителя. В клинике ЦНИИТ впервые в РФ и в мире обоснованы и внедрены краткосрочные режимы химиотерапии ТБ органов дыхания после хирургического лечения у детей и подростков. Первые результаты исследования свидетельствуют о том, что в соответствии с разработанными нами критериями сроки химиотерапии после хирургического лечения у большей части (69\%) детей старшего возраста и подростков могут составлять 
3-6 мес, в том числе и при множественной/широкой лекарственной устойчивости МБТ. Получен патент на изобретение № 2626509 от 28.07.2017 «Способ дифференцированного подхода к срокам химиотерапии после хирургического лечения».

\section{Заключение}

Таким образом, успехи, достигнутые к XXI веку в изучении ТБ, создают предпосылки для того, чтобы ликвидировать его эпидемию как в мире, так и в России, тем не менее говорить о близкой победе над ТБ пока рано.

Необходимыми мероприятиями по ускорению элиминации туберкулеза в России на сегодня являются поддержка научных исследований и разработок новых инструментов борьбы с ТБ; внедрение новых диагностических алгоритмов и ускоренных диагностических тестов для выявления ТБ, в том числе у ВИЧ-положительных и ВИЧ-отрицательных пациентов; разработка и быстрое внедрение новых организационных мероприятий для профилактики ТБ у детей, взрослых, в том числе у ВИЧ-инфицированных; разработка и внедрение пер- сонализированных, укороченных и эффективных режимов лечения больных ТБ с множественной/широкой лекарственной устойчивостью возбудителя, включающих хирургические и патогенетические методы; разработка новых эффективных противотуберкулезных препаратов; разработка и усовершенствование микробиологических и молекулярно-генетических методов для определения лекарственной устойчивости МБТ; укрепление кадрового потенциала, внедрение новых обучающих программ и новых национальных клинических рекомендаций с применением телекоммуникационных технологий.

\section{Источник финансирования}

Поисково-аналитическая работа, подготовка и публикация статьи осуществлены на личные средства автора.

\section{Конфликт интересов}

Автор данной статьи подтвердил отсутствие конфликта интересов, о котором необходимо сообщить.

\section{ЛИТЕРАТУРА}

1. WHO. Global Tuberculosis Report [Internet]. WHO; 2017 [cited 2017 Dec 1]. Available from: http://www.who.int/tb/publications/ global_report/en/.

2. Смирнова Т.Г., Андреевская С.Н., Черноусова Л.Н. Молекулярно-генетическая диагностика туберкулеза и ЛУ МБТ. В кн.: Туберкулез органов дыхания. Руководство для врачей. / Под ред. проф. Эргешова А.Э. - М.: ООО «Галлея-Принт»; 2017. - C. 213-224. [Smirnova TG, Andreevskaya SN, Chernousova LN. Moleculyarno-geneticheskaya diagnostika tuberkuleza i LU MBT. In: Pulmonary tuberculosis. Guidelines for physicians. Ed by Ergeshov A.E. Moscow: Galleya-Print; 2017. pp. 213-224. (In Russ).]

3. Ларионова Е.Е., Андриевская И.Ю. Микробиологические методы диагностики туберкулеза. В кн.: Туберкулез органов дыхания. Руководство для врачей. / Под ред. проф. Эргешова А.Э. - М.: ООО «Галлея-Принт»; 2017. - С. 203-213. [Larionova EE, Andrievskaya IYu. Microbiologicheskie methody diagnostiki tuberkuleza. In: Pulmonary tuberculosis. Guidelines for physicians. Ed by Ergeshov A.E. Moscow: Galleya-Print; 2017. pp. 203-213. (In Russ).]

4. Андреевская С.Н., Смирнова Т.Г., Черноусова Л.Н. Возбудитель туберкулеза: строение, генетика, физиология, лекарственная устойчивость, нетуберкулезные микобактерии. В кн.: Туберкулез органов дыхания. Руководство для врачей. / Под ред. проф. Эргешова А.Э. - М.: Галлея-Принт; 2017. - С. 10-33. [Andreevskaya SN, Smirnova TG, Chernousova LN. Vozbuditel' tuberkuleza: stroenie, genetika, fiziologiya, lekarstvennaya ustoichivost', netuberkuleznye mikobakterii. In: Pulmonary tuberculosis. Guidelines for physicians. Ed by Ergeshov A.E. Moscow: GalleyaPrint; 2017. pp. 10-33. (In Russ).]

5. Черноусова Л.Н., Андреевская С.Н., Смирнова Т.Г., и др. Лекарственно-устойчивый туберкулез: перспективы ускоренной диагностики // Бактериология. - 2017. - Т.2. - №1 C. 25-34. [Chernousova LN, Andreevskaya SN, Smirnova TG, et al. Drug-resistant tuberculosis: the prospects for accelerated diagnostics and chemotherapy. Bacteriologiya. 2017;2(1):25-34. (In Russ).]

6. Андреевская С.Н. Новейшие технологии в микробиологической диагностике туберкулеза. / Российская научно-практическая конференция молодых ученых с международным участием, посвященная всемирному Дню борьбы с туберкулезом «Современные инновационные технологии в эпидемиологии, диагностике и лечении туберкулеза взрослых и детей»; Март 22-23, 2018; Москва. [Andreevskaya SN. Noveishie tekhnologii v mikrobiologicheskoi diagnostike tuberkuleza. (Conference proceedings) Rossiiskaya nauchno-prakticheskaya konferentsiya molodykh uchenykh s mezhdunarodnym uchastiem, posvyashchennaya vsemirnomu dnyu bor'by s tuberkulezom: «Sovremennye innovatsionnye tekhnologii $\mathrm{v}$ epidemiologii, diagnostike i lechenii tuberkuleza vzroslykh i detei»; 2018 mar 22-23; Moscow. (In Russ).]

7. Патент РФ на изобретение RU № 2574917. Варламов Д.А., Сочивко Д.Г., Аляпкина Ю.С., и др. Реагент, позволяющий инактивировать микроорганизмы, экстрагировать и сохранять ДНК бактерий в форме, пригодной для высокоэффективной молекулярной диагностики. [Patent RUS № 2574917. Varlamov DA, Sochivko DG, Alyapkina YuS, et al. Reagent, pozvolyayushchii inaktivirovat' mikroorganizmy, ekstragirovat' i sokhranyat' DNK bakterii v forme, prigodnoi dlya vysokoeffektivnoi molekulyarnoi diagnostiki. (In Russ).] Доступно по: http://www.freepatent.ru/patents/2574917. Ссылка активна на 13.04.2018.

8. Черноусова Л.Н., Ларионова Е.Е., Смирнова Т.Г., и др. Фенотипическая чувствительность к противотуберкулезным препаратам штаммов M. tuberculosis с мутациями, ассоциированными с устойчивостью к рифампицину и изониазиду // Вестник ЦНИИТ. - 2017. - №1 - C. 10-18. [Chernousova LN, Larionova EE, Smirnova TG, et al. Phenotypic susceptibility to TB drugs in $\mathrm{M}$. tuberculosis strains with mutations associated with rifampicin- and isoniazid-resistance. CTRI Bulletin. 2017;(1):1018. (In Russ).]

9. Аляпкина Ю.С., Ларионова Е.Е., Смирнова Т.Г., и др. Изучение спектра и частоты встречаемости мутаций гена еmbB микобактерий туберкулезного комплекса, ассоциируемых с устойчивостью к этамбутолу, методом полимеразной цепной реакции в реальном времени // Туберкулез и болезни легких. 2017. - T.95. - №11 - C. 27-35. [Alyapkina YuS, Larionova EE, Smirnova TG, et al. Investigation of ranges and frequency of mutations in the embB gene in Mycobacterium tuberculosis associated with resistance to ethambutol using real-time polymerase chain 
reaction. Tuberculosis and Lung Diseases. 2017;95(11):27-35. (In Russ).] doi: 10.21292/2075-1230-2017-95-11-27-35.

10. Ergeshov A, Andreevskaya SN, Larionova EE, et al. The spectrum of mutations in genes associated with resistance to rifampicin, isoniazid, and fluoroquinolones in the clinical strains of M. tuberculosis reflects the transmissibility of mutant clones. Mol Biol. 2017;51(4):595-602. doi: 10.7868/S0026898417030041.

11. Mikhailovich V, Lapa S, Gryadunov D, et al. Identification of rifampin-resistant mycobacterium tuberculosis strains by hybridization, PCR, and ligase detection reaction on oligonucleotide microchips. J Clin Microbiol. 2001;39(7):2531-2540. doi: 10.1128/ JCM.39.7.2531-2540.2001.

12. Gryadunov D, Mikhailovich V, Lapa S, et al. Evaluation of hybridisation on oligonucleotide microarrays for analysis of drug-resistant Mycobacterium tuberculosis. Clin Microbiol Infect. 2005;11(7):531539. doi: 10.1111/j.1469-0691.2005.01183.x.

13. Антонова О.В. Грядунов Д.А., Лапа С.А., и др. Выявление мутаций в геноме Mycobacterium tuberculosis, приводящих к устойчивости к фторхинолонам методом гибридизации на биологических микрочипах // Бюллетень экспериментальной биологии и медицины. - 2008. - Т.145. - №1 - С. 115-121. [Antonova OV, Gryadunov DA, Lapa SA, et al. Detection of mutations in Mycobacterium tuberculosis genome determining resistance to fluoroquinolones by hybridization on biological microchips. Biull Eksp Biol Med. 2008;145(1):115-121. (In Russ).]

14. Петрова Л.В., Мельникова Е.И., Соловьев Ю.А., и др. Выявление нетуберкулезных микобактерий в Республике Марий Эл // Туберкулез и болезни легких. 2018. - Т.96. - №2 C. 41-46. [Petrova LV, Melnikova EI, Soloviev YuA, et al. Detection of non-tuberculous mycobacteria in Mari El republic. Tuberculosis and Lung Diseases. 2018;96(2):41-46. (In Russ).] doi: 10.21292/2075-1230-2018-96-2-41-46.

15. Шмелев Е.И., Ковалевская М.Н., Эргешов А.Э., и др. Микобактериозы в практике врача-пульмонолога: состояние проблемы // Практическая пульмонология. - 2016. - №3 C. 37-43. [Shmelev EI, Kovalevskaya MN, Ergeshov AE, et al. Pulmonary mycobacterioses: the state of problem. Prakticheskaya pulmonologiya. 2016;(3):37-43. (In Russ).]

16. Эргешов А.Э., Шмелев Е.И., Ковалевская М.Н., и др. Нетуберкулезные микобактерии у пациентов с заболеваниями органов дыхания (клинико-лабораторное исследование) // Пульмонология. - 2016. - Т.26. - №3 - С. 303-308. [Ergeshov AE, Shmelev EI, Kovalevskaya MN, et al. Nontuberculous mycobacteria in patients with respiratory diseases (a clinical study). Pulmonology. 2016;26(3):303-308. (In Russ).] doi: 10.18093/08690189-2016-26-3-303-308

17. Эргешов А.Э., Шмелев Е.И., Ковалевская М.Н., и др. Микобактериозы в практике врачей пульмонологов и фтизиатров // Туберкулез и болезни легких. - 2016. - Т.94. - №9 - С. 39-43. [Ergeshov AE, Shmelev EI, Kovalevskaya MN, et al. Mycobacteriosis in the practice of pulmonologists and phthisiologists. Tuberculosis and Lung Diseases. 2016;94(9):39-43. (In Russ).] doi: 10.21292/2075-1230-2016-94-9-39-43.

18. Устинова В.В., Смирнова Т.Г., Варламов Д.А., и др. Выявление и дифференциация нетуберкулезных микобактерий и микобактерий туберкулезного комплекса методом ПЦР в режиме реального времени // Туберкулез и болезни легких. 2016. - T.94. - №9 - C. 80-87. [Ustinova VV, Smirnova TG, Varlamov DA, et al. Detection and differentiation of nontuberculous mycobacteria and mycobacteria of MTBC by real-time PCR. Tuberculosis and Lung Diseases. 2016;94(9):80-87. (In Russ).] doi: 10.21292/2075-1230-2016-94-9-80-87.

19. Ustinova V, Smirnova T, Blagodatskikh K, et al. First draft genome sequence of a Mycobacterium gordonae clinical isolate. Genome Announc. 2016;4(3):e00638-16. doi: 10.1128/genomeA.00638-16.
20. Ustinova V, Smirnova T, Varlamov D, et al. Draft genome sequence of Mycobacterium heckeshornense clinical isolate. Genome Announc. 2018;6(13):e00178-18. doi: 10.1128/genomeA.00178-18.

21. Shitikov E, Ilina E, Chernousova L, et al. Mass spectrometry based methods for the discrimination and typing of mycobacteria. Infect Genet Evol. 2012;12(4):838-845. doi: 10.1016/j.meegid.2011.12.013.

22. Смирнова Т.Г., Воробьева А.В., Ларионова Е.Е., и др. MALDITOF масс-спектрометрия для видовой идентификации нетуберкулезных микобактерий // Туберкулез и болезни легких. 2011. - T.88. - №5 - C. 164-165. [Smirnova TG, Vorob'eva AV, Larionova EE, et al. MALDI-TOF mass spectrometry for species identification of nontuberculous mycobacteria. Tuberculosis and Lung Diseases. 2011;88(5):164-165. (In Russ).]

23. Андреевская С.Н., Андриевская И.Ю., Смирнова Т.Г., и др. Альтерации в генах pncA и rpsА и активность пиразинамидазы у штаммов M. tuberculosis фенотипически чувствительных и устойчивых к пиразинамиду // Вестник ЦНИИТ. - 2018. №2 - C. 74-84. [Andreevskaya SN, Andrievskaya IYu, Smirnova TG, et al. Alterations in the pncA and rpsA genes and pyrazinamidase activity in $\mathrm{M}$. tuberculosis strains with phenotypic sensitivity or resistance to pyrazinamide. CTRI Bulletin. 2018;(2):74-84. (In Russ).]

24. Панов Г.В., Андреевская С.Н., Ларионова Е.Е., и др. Анализ мутаций микобактерий туберкулеза, определяющих их лекарственную устойчивость у больных с нелеченым туберкулезом легких при разном ВИЧ-статусе в Свердловской области // Туберкулез и болезни легких. - 2017. - Т.95. - №2 - С. 27-32. [Panov GV, Andreevskaya SN, Larionova EE, et al. Analysis of mutations of tuberculous mycobacteria defining drug resistance in HIV-positive and HIV-negative tuberculosis patients without prior history of treatment in Sverdlovsk region. Tuberculosis and Lung Diseases. 2017;95(2):27-32. (In Russ).] doi: 10.21292/2075-12302017-95-2-27-32.

25. Ilina EN, Shitikov EA, Ikryannikova LN, et al. Comparative genomic analysis of Mycobacterium tuberculosis drug resistant strains from Russia. PLoS One. 2013;8(2):e56577. doi: 10.1371/ journal.pone.0056577.

26. Афанасьев М.В., Икрянникова Л.Н., Ильина Е.Н., и др. Применение реакции мини-секвенирования с последующим MALDI-TOF масс-спектрометрическим анализом для оценки устойчивости к рифампицину и изониазиду штаммов Mycobacterium tuberculosis // Проблемы туберкулеза и болезней легких. - 2007. - T.84. - №7 - C. 37-42. [Afanas'ev MV, Ikryannikova LN, Ilina EN, et al. Primenenie reaktsii minisekvenirovaniya s posleduyushchim MALDI-TOF mass-spectrometricheskim analizom dlya otsenki ustoichivosti k rifampitsinu i izoniazidu shtammov Mycobacterium tuberculosis. Probl Tuberk Bolezn Legk. 2007;84(7):37-42. (In Russ).]

27. Ikryannikova LN, Afanas'ev MV, Akopian TA, et al. Mass-spectrometry based minisequencing method for the rapid detection of drug resistance in Mycobacterium tuberculosis. J Microbiol Methods. 2007;70(3):395-405. doi: 10.1016/j.mimet.2007.05.015.

28. Карачунский М.А., Черноусова Л.Н. Молекулярная эпидемиология туберкулеза // Проблемы туберкулеза и болезней легких. - 2007. - Т.84. - №4 - C. 3-7. [Karachunsky MA, Chernousova LN. Molekulyarnaya epidemiologiya tuberkuleza Probl Tuberk Bolezn Legk. 2007;84(4):3-7. (In Russ).]

29. Панов Г.В., Андреевская С.Н., Ларионова Е.Е., и др. Сполиготипирование штаммов микобактерий, выделенных от ВИЧотрицательных и ВИЧ-положительных больных туберкулезом Свердловской области // Бактериология. - 2017. - Т.2. №2 - C. 14-19. [Panov GV, Andreevskaya SN, Larionova EE, et al. Spoligotyping of M. tuberculosis strains, isolated from HIVpositive and HIV-negative TB patients of Sverdlovsk region. Bacteriologiya. 2017;2(2):14-19. (In Russ).] 
30. Аксенова В.А., Барышникова Л.А., Сокольская Е.А. Новые возможности диагностики туберкулезной инфекции у детей и подростков // Российский вестник перинатологии и педиатрии. - 2011. - T.56. - №4 - C. 90-96. [Aksenova VA, Baryshnikova LA, Sokolskaya EA. New possibilities for the diagnosis of tuberculosis infection in children and adolescents. Rossyiskii vestnik perinatologii i pediatrii (Russian Bulletin of Perinatology and Pediatrics). 2011;56(4):90-96. (In Russ).]

31. Смирнова Т.Г., Андреевская С.Н., Ларионова Е.Е., и др. Мониторинг видового разнообразия нетуберкулезных микобактерий в ряде областей РФ с использованием ДНК-стрипов genotype Mycobacterium CM/AS (Hain Lifescience, Германия) // Туберкулез и болезни легких. - 2017. - Т.95. - №5 - С. 54-59. [Smirnova TG, Andreevskaya SN, Larionova EE, et al. Monitoring of species diversity of non-tuberculosis mycobacteria in the some Russian regions using DNA-strips of genotype mycobacterium CM/ AS (Hain Lifescience, Germany). Tuberculosis and Lung Diseases. 2017;95(5):54-59. (In Russ).] doi: 10.21292/2075-1230-2017-955-54-59

32. Dogra S, Narang P, Mendiratta DK, et al. Comparison of a whole blood interferon-gamma assay with tuberculin skin testing for the detection of tuberculosis infection in hospitalized children in rural India. J Infect. 2007;54(3):267-276. doi: 10.1016/j. jinf.2006.04.007.

33. Hill PC, Brookes RH, Adetifa IM, et al. Comparison of enzymelinked immunospot assay and tuberculin skin test in healthy children exposed to Mycobacterium tuberculosis. Pediatrics. 2006;117(5):1542-1548. doi: 10.1542/peds.2005-2095.

34. Tsiouris SJ, Coetzee D, Toro PL, et al. Sensitivity analysis and potential uses of a novel gamma interferon release assay for diagnosis of tuberculosis. J Clin Microbiol. 2006;44(8):2844-2850. doi: 10.1128/JCM.02411-05.

35. Pinto LM, Grenier J, Schumacher SG, et al. Immunodiagnosis of tuberculosis: state of the art. Med Princ Pract. 2012;21(1):4-13. doi: 10.1159/000331583.

36. Rutherford M, Alisjahbana B, Maharani W, et al. Sensitivity of the quantiferon-gold in-tube assay in sputum smear positive TB cases in Indonesia. PLoS One. 2010;5(8):e12020. doi: 10.1371/journal. pone. 0012020 .

37. Sargentini V, Mariotti S, Carrara S, et al. Cytometric detection of antigen-specific IFN-gamma/IL-2 secreting cells in the diagnosis of tuberculosis. BMC Infect Dis. 2009;9:99. doi: 10.1186/1471-23349-99.

38. El Fenniri L, Toossi Z, Aung H, et al. Polyfunctional Mycobacterium tuberculosis-specific effector memory CD4+ $\mathrm{T}$ cells at sites of pleural TB. Tuberculosis (Edinb). 2011;91(3):224-230. doi: 10.1016/j.tube.2010.12.005.

39. Petruccioli E, Petrone L, Vanini V, et al. IFN $\gamma / \mathrm{TNF} \alpha$ specific-cells and effector memory phenotype associate with active tuberculosis. J Infect. 2013;66(6):475-486. doi: 10.1016/j.jinf.2013.02.004.

40. Никитина И.Ю. Особенности дифференцировки лимфоцитов CD4 у больных туберкулезом легких: Автореф. дис. ... канд. мед. наук. - M.; 2013. - 25 c. [Nikitina IYu. Osobennosti dif- ferentsirovki limfotsitov CD4 u bol'nykh tuberkulezom legkikh. [dissertation abstract] Moscow; 2013. 25 р. (In Russ).] Доступно по: http://medical-diss.com/medicina/osobennosti-differentsirovkilimfotsitov-cd4-u-bolnyh-tuberkulezom-legkih. Ссылка активна на 22.04.2018.

41. Scheffer GL, Pijnenborg AC, Smit EF, et al. Multidrug resistance related molecules in human and murine lung. J Clin Pathol. 2002;55(5):332-339. doi: 10.1136/jcp.55.5.332.

42. Fletcher JI, Williams RT, Henderson MJ, et al. ABC transporters as mediators of drug resistance and contributors to cancer cell biology. Drug Resist Updat. 2016;26:1-9. doi: 10.1016/j.drup.2016.03.001.

43. Ерохина М.В., Лепеха Л.Н., Эргешов А.Э. Возможность формирования устойчивости моноцитарных и эпителиальных клеток к рифампицину // Туберкулез и социально значимые заболевания. - 2016. - №2 - C. 59-65. [Erokhina MV, Lepekha LN, Ergeshov AE. Formation of resistance to rifampicin in monocyte-macrophagic and epithelial cell lines. Tuberkulez $i$ sotsial'no znachimye zabolevaniya. 2016;(2):59-65. (In Russ).]

44. Лепеха Л.Н., Ерохина М.В., Бурцева С.А., и др. Функциональная морфология легких: современные аспекты. В сб.: Туберкулез в ХХІ веке: проблемы и пути решения. / Под ред. Эргешова А.Э. М.: ФГБНУ «ЦНИИТ», Галлея-Принт; 2015. - С. 20-35. [Lepekha LN, Erokhina MV, Burtseva SA, et al. Funktsional'naya morfologiya legkikh: sovremennye aspekty. In: Tuberkulyoz v XXIveke: problemy i puti resheniya. Ed by Ergeshov A.E. Moscow: FGBNU «CNIIT», Galleya-Print; 2015. pp. 20-35. (In Russ).]

45. Ерохина М.В., Незлин Л.П., Авдиенко В.Г., и др. Иммуногистохимическое выявление Mycobacterium tuberculosis в ткани легких у больных туберкулезом с использованием лазерной сканирующей микроскопии // Известия Российской академии наук. Серия биологическая. - 2016. - №1 - C. 27-31. [Erokhina MV, Nezlin LP, Avdienko VG, et al. Immunohistochemical detection of Mycobacterium tuberculosis in tissues of consumptives using laser scanning microscopy. zv Akad Nauk Ser Biol. 2016;(1):27-31. (In Russ).] doi: 10.7868/S0002332916010057.

46. Буракова М.В., Васильева И.А., Ваниев Э.В., и др. Эффективность химиотерапии туберкулеза легких у впервые выявленных пациентов при разных сроках определения множественной лекарственной устойчивости возбудителя // Туберкулез и болезни легких. - 2017. - Т.95. - №11 - C. 63-68. [Burakova MV, Vasilyeva IA, Vaniev EV, et al. Efficiency of pulmonary tuberculosis chemotherapy in new cases depending on the time of drug resistance detection. Tuberculosis and Lung Diseases. 2017;95(11):63-68. (In Russ).] doi: 10.21292/2075-1230-2017-9511-63-66.

47. Тихонов А.М., Буракова М.В., Ваниев Э.В., и др. Эффективность химиотерапии с применением бедаквилина у больных туберкулезом легких с лекарственной устойчивостью возбудителя // Туберкулез и болезни легких. - 2018. - T.96. - №2 C. 22-26. [Tikhonov AM, Burakova MV, Vaniev EV, et al. Efficiency of chemotherapy with bedaquiline in drug resistant pulmonary tuberculosis patients. Tuberculosis and Lung Diseases. 2018;96(2):22-26. (In Russ).] doi: 10.21292/2075-1230-2018-96-2-22-26.

\section{КОНТАКТНАЯ ИНФОРМАЦИЯ}

Эргешов Атаджсан Эргешович, Д.м.н., профессор [Atadzhan E. Ergeshov, MD, PhD, Professor] Адрес: 107564, Москва, Яузская аллея, д. 2, тел.: +7 (499) 785-90-19, e-mail: cniit@ctri.ru, SPIN-код: 8372-1666, ORCID: https://orcid.org/0000-0002-2494-9275 